\title{
2 Sex-dependent personality in two invasive species of mosquitofish
}

Biological Invasions, 2020, 22, pages 1353-1364. Doi: 10.1007/s10530-019-02187-3

4 Marcus Michelangeli ${ }^{1,2, *}$, Julien Cote ${ }^{2,3}$, David G. Chapple ${ }^{1}$, Andrew $\operatorname{Sih}^{2}$, Tomas Brodin ${ }^{2,4}$,

5 Sean Fogarty ${ }^{2}$, Michael G. Bertram ${ }^{1}$, Jack Eades ${ }^{1}$, and Bob B. M. Wong ${ }^{1}$.

6

$7 \quad{ }^{1}$ Monash University, School of Biological Sciences, Melbourne, 3800, Australia

$8{ }^{2}$ Department of Environmental Science and Policy, University of California, Davis, CA

995616 USA

$10{ }^{3}$ Laboratoire Évolution and Diversité Biologique (EDB UMR 5174), Université de Toulouse,

11 CNRS, IRD, UPS, 118 route de Narbonne, Toulouse 31062, France.

$12{ }^{4}$ Department of Wildlife, Fish and Environmental Studies, Swedish University of Agricultural

13 Sciences. SE-901 83 Umeå, Sweden

14

*Correspondence: marcus.michelangeli@gmail.com

16

17

18

19

20

21

22

23

24

25

26

27

28

29

30 
36 A key challenge in invasion biology is identifying characteristics that allow some species to 37 be repeatedly successful at invading novel environments. Invasions can often be 38 disproportionately driven by a single sex, with differences in behavioural mechanisms 39 between the sexes potentially underlying sex-biased invasiveness. Here, we took an animal 40 personality approach to study the behaviour of two repeatedly successful congeneric invasive 41 species, the western mosquitofish, Gambusia affinis, and the eastern mosquitofish, Gambusia holbrooki. In each species, we investigated whether males and females shared common personality traits (i.e. behavioural types and behavioural syndromes), with the aim of 44 identifying possible behavioural mechanisms that could help explain why mosquitofish invasions are often characterised by sex-biased founder populations. We found sex-dependent personality, although sex differences varied between species. Specifically, male G. affinis were bolder and less social than female G. affinis, whereas we found no behavioural type differences between the sexes in G. holbrooki. We also found a consistent correlation between boldness and exploration in both sexes within G. affinis, but this correlation was weak in G. holbrooki. Finally, exploration was also correlated with sociability in male $G$. affinis, but not in females. Our results suggest that behavioural tendencies may diverge, both among species and between the sexes, because of adaptation experienced during different invasion pathways. Broadly, identifying the behavioural mechanisms that predict an individual's 'invasiveness' may be difficult to tease apart between species because each invasion is characterised by different abiotic and biotic interactions that likely require different suites of behaviours. Future studies are needed to elucidate whether, in fact, personality variation between the sexes can mediate the occurrence of sex-biased invasions.

Keywords: Individual variation, Animal personalities, Invasion syndrome, Invasion process, 
61 Individuals that successfully invade and establish into new areas often represent a nonrandom subset of the population, and typically consist of individuals that possess a certain suite of characteristics that differs from those of non-invaders (Blackburn \& Duncan 2001, Tingley et al. 2010, Renault et al. 2018). For instance, it has been proposed that these individuals often have behavioural and life-history traits that increases their propensity to be transported to new environments, exploit novel resources, establish viable populations, and spread and colonise new habitats (Holway \& Suarez 1999, Chapple et al. 2012, Chapple \& Wong 2016, Rehage et al. 2016). These same phenotypic traits also mediate how invaders interact with the local environment and native biota, and thus play a pivotal role in determining the ecological and evolutionary impacts of an invasion (Phillips \& Suarez 2012). Hence, a key challenge in invasion biology is identifying the characteristics that allow some species to be repeatedly successful at invading and colonising novel environments (Chapple et al. 2012).

Evidence is starting to accumulate that biological invasions can be often be disproportionately driven by a single sex (Gutowsky \& Fox 2011, Miller et al. 2013, Rebrina et al. 2015). Skewed sex ratios at the leading edge of an invasion have been shown to have profound consequences for population growth and persistence (Miller et al. 2013, Shaw et al. 2018), and can lead to greater adverse impacts on native communities than non-skewed sex ratios (Fryxell et al. 2015). For instance, female-biased invasion front populations can exponentially increase the pace of an invasion by speeding up population growth, resulting in a higher probability of colonisation success (Miller et al. 2013), whereas male-biased invasions may be more likely to competitively exclude native species, creating new opportunities for habitats and resources to be exploited (Duckworth \& Baydeav 2007, 
85 Gutowsky \& Fox 2011). However, despite the prevalence of sex-biased invasions, the mechanisms that lead to biased sex ratios at the front of an invasion have rarely been studied.

Sex-biased invasions likely occur because males and females often differ considerably in lifehistory and behavioural traits related to invasion (Shaw et al. 2018). For example, dispersal is the mechanism that allows invaders to spread from the point of introduction into new areas and thus is a pivotal component of the invasion process (Cote et al. 2010a), but males and females often differ in their propensity to disperse (Trochet et al. 2016), and in traits related to dispersal (e.g. morphology: Llewelyn et al. 2010; behaviour: Marentette et al. 2011). Such sex-dependent traits (e.g. sex-biased dispersal) may enhance the invasiveness of a single sex, leading to biased sex ratios (Miller \& Inouye 2013, Fryxell et al. 2015, Shaw et al. 2018). Alternatively, limited behavioural variation between the sexes would be less vulnerable to selective filtering by the invasion process, and thus leading-edge populations would not be expected to be disproportionately skewed towards a particular sex (Michelangeli et al. 2016a, Gruber et al. 2017).

101 One relatively new approach to investigating the role of behaviour in invasions is through the study of animal personalities (see reviews: Cote et al. 2010a, Chapple et al. 2012, Sih et al. 2012, Juette et al. 2014). Animal personality refers to the concept that individuals within

104 populations often show consistent differences in a range of behaviours (i.e. behavioural 105 types: Sih et al. 2004), and these behaviours can covary across time/and or context (i.e. behavioural syndrome; Sih et al. 2004). Personality traits are often linked to life-history

107 (reproduction and growth rates: Biro \& Stamps 2008), ecological processes (habitat specialisation: Michelangeli et al. 2018a), and social roles within populations and

109 communities (e.g. innovation \& cultural transmission: Aplin et al. 2015). Given its direct 
110 bearing on fitness, an individual's personality should also influence its probability of

111 transitioning through the invasion process, with different behavioural types being

112 advantageous at different stages of invasion (Cote et al. 2010a, Fogarty et al. 2011, Chapple

113 et al. 2012, Chapple \& Wong 2016). Indeed, mounting evidence suggests that invasive

114 individuals may exhibit combinations of behaviours that are beneficial in outcompeting

115 native species (Pintor et al. 2009), dispersing into new habitats (Michelangeli et al. 2017),

116 and avoiding novel predators (Mennen \& Laskowski 2018). In this regard, personality

117 differences between the sexes could underlie differences in sex-biased dispersal and sex-

118 biased invasiveness (Michelangeli et al. 2016a, Mishra et al. 2018). Sex differences in the

119 direction and magnitude of behavioural syndromes could arise due to divergent selection

120 pressures and life-histories after maturation. This may be particularly true for sexually

121 dimorphic species, as marked differences in morphology (e.g. body size) can induce variance

122 in behaviour (Shine 1989, Fairbairn et al. 2007). For instance, larger body size requires

123 higher energetic input and, thus, personality traits that are associated with an increase in

124 feeding rate (Biro \& Stamps 2008). If personality influences an individual's level of

125 'invasiveness' and, hence, their potential impact on the environment, it is important to

126 consider how the sexes might differ in personality to better understand the behavioural

127 mechanisms involved in successful invasions.

129 In this study, we compared the personality traits of males and females in congeneric invasive

130 species, the western mosquitofish, Gambusia affinis (Baird \& Girard 1853) and the eastern

131 mosquitofish, Gambusia holbrooki (Girard 1859). These species provide an ideal opportunity

132 to explore sex differences in personality traits related to invasion for several reasons. First,

133 Gambusia are small live-bearing freshwater fish that show pronounced sexual size

134 dimorphism, whereby females are commonly much larger than males (Pyke 2005). Second, 
135 both species have undergone numerous deliberate (i.e. introduced as a biocontrol tool for 136 mosquitoes) and accidental introductions, and have now spread and become invasive

137 globally, placing them within the top 100 of the world's most invasive species (Pyke 2008).

138 Third, invasive populations are often characterised by demographic differences in sex ratios

139 that can either be skewed towards males or females (Fryxell et al. 2015). Fourth, 140 mosquitofish are having tremendous adverse impacts on native insect, amphibian and fish 141 communities worldwide (Pyke 2008, Schluse et al. 2013). Importantly, some studies suggest 142 that the magnitude of these impacts are dependent upon both the sex ratio (Fryxell et al. 143 2015), and the personality composition of invading populations (Cote et al. 2017). Thus, 144 understanding the behavioural mechanisms driving Gambusia invasions is an issue of 145 immediate importance.

147 The approach used in this study allowed us to determine if each species and sex share 148 common behavioural syndromes and, in so doing, provides insights into the behavioural traits 149 that might contribute to invasiveness. We hypothesised that males and females would differ 150 in a range of behaviours related to invasion, but that these differences would vary among species due to the divergent introduction pathways and local environmental conditions experienced by each species.

154 METHODS

\section{Species collection and husbandry}

156 Gambusia holbrooki (female: $n=25$; male: $n=25$ ) were collected from the Science Centre

157 Lake ( $37^{\circ} 54^{\prime} 28^{\prime \prime} \mathrm{S}, 145^{\circ} 08^{\prime} 16^{\prime \prime} \mathrm{E}$; 10:14 h light:dark), Monash University, Victoria, 158 Australia on 22 January 2014. All fish were caught via seine netting to minimise potential 159 personality-biased sampling (Michelangeli et al. 2016b). Fish were housed individually in 
160 glass holding tanks (30 cm length $\times 15 \mathrm{~cm}$ width $\times 20 \mathrm{~cm}$ height $)$ and acclimated to

161 laboratory conditions for 1 month prior to experimentation. We housed fish individually in

162 order to keep track of their identity during behavioural assays. Throughout the housing

163 period, fish were kept at a temperature of $24-26^{\circ} \mathrm{C}$, and under a 12:12 h light:dark cycle.

164 Both during housing and throughout experimentation, fish were fed ad libitum with 165 commercial fish food.

166

167 Gambusia affinis (female: $n=110$; male: $n=112$ ) were supplied by the Sacramento-Yolo 168 Mosquito and Vector Control District. These fish represent a mix of hatchery-reared and 169 field-collected fish. Fish were transported to the Centre for Aquatic Biology and Aquaculture 170 (CABA), University of California Davis on 18 March 2008, and housed in groups of $\sim 60$ in $80 \mathrm{~L}$ flow-through fibreglass tanks, and acclimated to laboratory conditions for 1 month prior to experimentation. All individuals were marked with a minimally invasive elastomer tag

173 (northwest Marine Technologies, Shaw Island, WA, USA) under a low dose $\left(5 \mathrm{mg} \mathrm{L}^{-1}\right)$ of 174 anaesthetic (MS-222). Each individual received a randomly assigned unique identifier by 175 injecting one of four colours subcutaneously into four locations on the caudal peduncle (two on each side). Throughout the housing period, fish were kept at a constant temperature (22$\left.23{ }^{\circ} \mathrm{C}\right)$ on a natural photoperiod $(14: 10 \mathrm{~h}$ light:dark), and were fed commercial fish food $a d$ libitum.

\section{Behavioural assays}

181 For both species, in order to characterise personality types of each sex, we ran two behavioural assays, each separated by $1 \mathrm{~h}$. First, we tested sociability by quantifying the tendency of individuals to shoal. Second, we tested individual boldness and exploratory

184 behaviours. The former was characterised by the latency of fish to exit from a refuge and 
enter a novel environment, and the latter was quantified by recording the movement and space use of fish after exiting the refuge. These behaviours represent an individual's reaction to a social context and to a novel environment, respectively. Both sets of behaviours are hypothesised to play an important role in colonising new environments (Chapple et al. 2012,

189 Sih et al. 2012, Chapple \& Wong 2016). Behavioural assays were repeated for G. holbrooki a

190 day later. We consider both repeats of the G. holbrooki behavioural assays in this study because it adds more precision to the dataset given the relatively small sample size when compared to the G. affinis dataset. We do not calculate repeatability in this study, but these behaviours have previously been found to be repeatable in both species (G. affinis: Cote et al. 2010, 2011, 2013; G. holbrooki: Wilson et al. 2010, Polverino et al. 2018).

\section{Tendency to shoal (sociability)}

197 To measure social behaviour, we recorded the amount of time an individual spent near a 198 shoal of conspecifics (sensu Ward et al. 2004, Bertram et al. 2018). The experimental 199 aquarium $(50 \mathrm{~cm}$ length $\times 25 \mathrm{~cm}$ width $\times 30 \mathrm{~cm}$ height $)$ was divided lengthwise into three 200 compartments (two small and one large central compartment) using two transparent glass partitions $12.5 \mathrm{~cm}$ from each end of the tank. The partitions allowed visual, but not physical or olfactory, interaction between the shoal and the focal individual. A randomly designated stimulus shoal was introduced to one of the smaller compartments $1 \mathrm{~h}$ before the experiment began, while the other small compartment was left empty as a control. Stimulus shoals were comprised of 14 mosquitofish (seven conspecific males and seven conspecific females) that had no previous experience with the focal individual. After $1 \mathrm{~h}$, the focal fish was introduced into an opaque cylinder in the centre of the larger, central compartment and given $10 \mathrm{~min}$ to acclimate. At the end of the acclimation period, the cylinder surrounding the focal fish was remotely removed to allow the fish access to the central compartment with minimal 
210 disturbance. The position of the focal fish was continuously recorded for $10 \mathrm{~min}$. The large

211 compartment was divided with vertical marks every $2 \mathrm{~cm}$, and the time spent by the focal fish

212 within the $2 \mathrm{~cm}$ closest to the stimulus shoal was recorded. At the conclusion of the trial, 213 individuals were returned to their holding aquaria.

\section{Boldness and exploration in a novel environment}

216 One hour after the sociability assay, boldness and exploration were assessed by recording

217 behaviour in a novel environment. The experimental arenas differed slightly for data 218 collected on each species. For G. affinis, the experimental arena was an opaque, white plastic 219 tank (80 cm length $\times 80 \mathrm{~cm}$ width $\times 20 \mathrm{~cm}$ height $)$ filled with $10 \mathrm{~cm}$ of water, and furnished 220 with half flower pots in two corners, which served as additional refuges. For G. holbrooki, the experimental arena consisted of a glass aquarium $(60 \mathrm{~cm}$ length $\times 30 \mathrm{~cm}$ width $\times 30 \mathrm{~cm}$ height), filled with $15 \mathrm{~cm}$ of water, with 72 equal grid squares marked on its base. For both species, focal fish were added gently to an upright, cylindrical $(9-10 \mathrm{~cm}$ diameter) opaque PVC pipe refuge on one side of the experimental arena. After $10 \mathrm{~min}$, a $4 \mathrm{~cm}$ wide door to the refuge chamber was remotely opened, allowing fish access to the experimental arena. We then allowed the fish 45 min to leave the refuge, recording the time to exit. After the fish left the refuge, we then allowed an additional $5 \mathrm{~min}$ to explore the novel environment. Because we gave fish an additional $5 \mathrm{~min}$ to explore the novel environment after it left the refuge, we treated both behavioural measures as independent behavioural traits. Trials ended either 5 min after fish left the refuge or after $45 \mathrm{~min}(2700 \mathrm{~s})$ if animals did not leave the refuge.

232 For both species, boldness was measured as the maximum time allowed for fish to exit the 233 refuge (2700 s) minus the latency (s) to exit from the refuge, and to stay for greater than 10 234 consecutive seconds out of the refuge. Shorter latency to exit the refuge indicates a higher 
235 boldness and is regularly used as a metric for boldness in studies of fish (Moran et al. 2016,

236 Hulthén et al. 2017), including mosquitofish (Wilson et al. 2010, Bertram et al. 2018,

237 Polverino et al. 2018). Exploratory behaviour was quantified by measuring how much of the

238 experimental arena the focal individual covered. For $G$. affinis, the area explored

239 incorporated both the distance an individual moved and the spatial pattern of those

240 movements. Given $\mathrm{x}$ - y coordinates from each video frame, each individual's continuous

241 path was tracked, and the area an individual explored was calculated as the percentage of the

242 arena that fell within $5 \mathrm{~cm}$ of the fish's path. For $G$. holbrooki, the area explored was

243 calculated by dividing the total number of unique grid-squares an individual entered by the

244 total number of grid squares $(n=72)$.

Morphological measurements

247 All fish were weighed and measured before and after the behavioural assays. G. affinis were 248 larger than G. holbrooki for both sexes (mean male total body length (TBL) \pm standard error 249 (SE): G. affinis: $23.07 \pm 0.25 \mathrm{~mm}$, G. holbrooki: $21.45 \pm 0.28 \mathrm{~mm}$, Mann-Whitney test: $U=$ 250 1858, $p<0.001$; mean female TBL \pm SE: G. affinis: $29.34 \pm 0.56 \mathrm{~mm}$, G. holbrooki: $25.78 \pm$ $0.37 \mathrm{~mm} ; U=1890, p<0.001)$.

\section{Statistical analysis}

254 Data were analysed in $\mathrm{R}$ version 3.3.2 ( $\mathrm{R}$ Core Development Team 2016). Residuals were 255 checked for normality (Shapiro-Wilk test: Royston 1995) and homogeneity of variance 256 (Fligner-Killeen test: Conover et al. 1981). Prior to analysis, time spent in the $2 \mathrm{~cm}$ social zone (i.e. sociability) was rank-transformed, and latency to exit the refuge was logtransformed, to approximate Gaussian error distributions. Because each species was reared under different conditions and there were slight differences in the design of behavioural 
assays, we ran separate statistical tests for each species. Thus, any species-level comparison is based upon a comparison of two separate models and not statistically computed. Statistical significance was assigned at $\alpha=0.05$.

264 We first tested whether the sexes differed in the individual behavioural traits studied using 265 linear models for the G. affinis dataset, and linear mixed-effects models (LMM; package Ime4, Bates et al. 2015) for the G. holbrooki dataset. Models contained the fixed effects of sex, body length and a sex $\times$ body length interaction. We also included trial number and sex $\times$ trial number interaction as fixed factors, and individual ID as a random factor within the mixed-effects models in order to consider the repeated measures design of the G. holbrooki dataset. P-values of interaction terms were calculated using likelihood ratio tests $\left(G^{2}\right)$ for LMM's (Bolker et al. 2009) and Wald's F-tests were used for linear models. If interaction terms were non-significant they were removed from the final models.

274 We assessed trait correlations within species and sex to determine the presence of 275 behavioural syndromes. To do this, we estimated the magnitude of pairwise relationships between behavioural traits using spearman-rank correlations and compared the correlation coefficients using the Fisher $z$-transformations.

\section{RESULTS}

280 1. Behavioural types

1a) Gambusia holbrooki

282 We found no effect of sex, trial or body length on $G$. holbrooki shoaling behaviour or time 283 taken to re-emerge from the refuge $(p<0.05$, Table 1; Figure 1). Regardless of sex, fish 284 explored more of the novel environment in trial 2 compared to trial 1, suggesting habituation 
to the experimental arena $\left(t_{1,49}=2.77, p=0.008\right.$; Table 1$)$. However, there was no effect of sex or body length on the exploratory behaviour of $G$. holbrooki $(p<0.05$, Table 1, Figure 1$)$.

\section{1b) Gambusia affinis}

Female G. affinis spent more time shoaling than male G. affinis $\left(\mathrm{t}_{1,219}=2.632, p=0.009\right.$;

Table 2, Figure 1). Regardless of sex, larger fish spent less time shoaling with conspecifics than smaller fish, although the effect of body length was marginally non-significant $\left(t_{1,219}=-\right.$ body length interaction: $\mathrm{F}_{1,218}=5.394, p=0.021$; Table 2), with smaller males re-emerging faster from the refuge than larger males $\left(t_{1,110}=-2.326, p=0.022\right)$. We found no effect of sex or body length on the tendency to explore the novel environment $(p<0.05$, Table 2$)$.

\section{Behavioural syndromes}

\section{2a) Gambusia holbrooki}

300 We found weak evidence of a behavioural syndrome in G. holbrooki. There was a marginal positive correlation between time to re-emerge from the refuge (boldness) and tendency to explore the novel environment (exploration) in females, but this correlation was negative in males (Table 3; Figure 2).

\section{2b) Gambusia affinis}

306 We found a significant positive correlation between the time taken to exit the refuge

307 (boldness) and tendency to explore the novel environment (exploration) in both male and

308 female G. affinis (Table 3; Figure 2). There was also evidence that time spent shoaling with 309 conspecifics (sociability) and tendency to explore the novel environment (exploration) were 
310 positively correlated in male G. affinis (Table 3). This correlation was not present in females,

311 but the correlation coefficients did not significantly differ between the sexes (Table 3 ).

\section{DISCUSSION}

314 We found evidence for sex-specific personality in invasive mosquitofish, but that these sex

315 differences varied depending on species. Specifically, male G. affinis were bolder and less

316 social than female G. affinis, but we found no behavioural type differences between the sexes

317 in G. holbrooki. There was also a positive correlation between boldness and exploration

318 within G. affinis, which was consistent in magnitude and direction in both males and females.

319 Notably, however, we also found that sociability was correlated to exploration in male $G$.

320 affinis, but not in females. There was only a weak positive correlation between boldness and exploration in female $G$. holbrooki, but this correlation was negative in males. The absence of

a common behavioural syndrome between Gambusia species is inconsistent with the hypothesis that there is a specific suite of behaviours that might help to explain both species' successful invasion history. Instead, our results suggest that behavioural tendencies may diverge among species and between the sexes because of adaptation experienced during different invasion pathways.

Sex differences in boldness and sociability in G. affinis are likely a product of disparate reproductive and life-history strategies. Females often bear a higher cost of reproduction than males, resulting in females having life-history and behavioural traits associated with a slower pace-of-life that maximises fecundity and reproductive output (e.g. longer life span, less risktaking; Debecker et al. 2016). Indeed, fecundity selection is a major evolutionary force selecting for larger body size in females in sexually size-dimorphic species (Shine 1989), and

334 higher levels of risk-taking have previously been linked to lower fecundity in female 
mosquitofish (Wilson et al. 2010). Females also tend to be more social than males and utilise the anti-predator benefits of group shoaling (i.e. dilution effects: Foster \& Treherne 1981, increased vigilance: Hoare et al. 2000) as a risk-avoidance strategy. Shoaling has also been shown to reduce the foraging and reproductive costs of sexual harassment by males of female mosquitofish (Pilastro et al. 2003). In several aquatic organisms, females have also been

340 shown to be less bold than males (Harris et al. 2010, King et al. 2013, Biro et al. 2014,

341 Debecker et al. 2016). Such low risk-taking behaviour may be particularly important for female mosquitofish, which may be preferentially targeted by predators as they are larger than males, and consequently represent more profitable prey (Britton \& Moser 1982). Interestingly, we also found in the current study that larger males took longer to re-emerge from the refuge than smaller males. This result corroborates with the idea that being larger makes you more vulnerable to predators, thus larger individuals adopt less risky behavioural strategies. On the other hand, smaller male G. affinis may have been faster to exit the refuge because the costs associated with hiding, such as the loss of reproductive opportunities (Martín et al. 2003), outweigh the benefits of such risk-avoidance behaviours. Indeed, male mating success is typically highly variable, particularly for smaller males who are often perceived as lower quality mates by females (Tomkins et al. 2018), which likely encourages a 'high risk, high reward' behavioural strategy in these smaller males (King et al. 2013).

It is somewhat surprising, then, that we did not find the same differences in boldness and sociability between male and female G. holbrooki. A possible explanation for this lack of divergence in boldness and social traits is that G. holbrooki, in this study, were sourced from an environment with low predation pressure, and thus the risk of emerging from a refuge and the benefits of shoaling in a group were perceived by females to be low, resulting in females being equally likely to take 'risks' as males. An alternative reason for a lack of sex 
360 differences in G. holbrooki more broadly is that the body range size of our study population

361 was different to the natural variation in body size observed in other wild populations (e.g.

362 McPeek 1992). The size differences between males and females in G. holbrooki was

363 comparatively smaller than G. affinis, thus the costs associated with having larger body size

364 may not be as robust in our G. holbrooki population, favouring selection towards similar

365 behavioural tendencies between the sexes (Fairbairn et al. 2007).

366

367 We observed markedly different personality traits between species. A consistent behavioural correlation between boldness and exploration was present in male and female G. affinis, but this correlation was weak in G. holbrooki. Indeed, observed behavioural differences between species are limited by the fact that we only compared one population of each species with unequal sample sizes. Thus, these results should be interpreted with much caution as our study does not offer a robust test of species differences, which was not the main aim of this research. However, past studies have found differences in behavioural traits between $G$. affinis and G. holbrooki (e.g. dispersal: Rehage \& Sih 2004; antipredator response: Rehage et al. 2005). In this study, behavioural differences between species could be a result of differences in the level of predation pressure along the introduction pathway and/or the local environment. Our finding that a boldness-exploration behavioural syndrome differed between species is consistent with most comparative studies on behavioural correlations, which have found remarkable variation in syndromes, particularly those related to boldness (Bell \& Sih

380 2007, Dingemanse et al. 2007; Michelangeli et al. in press). These studies suggest that highconsistency in behavioural syndromes are often linked to high-predation sites that place consistent selection on groups of behaviours, particularly behaviours linked to risk taking, compared to more benign environments which favour variable behavioural strategies

384 (Heinen-Kay et al. 2016). For example, in three-spine sticklebacks, Gasterosteus aculeatus 
385 (Linnaeus, 1758), populations raised in high predation risk environments exhibit a boldnessaggression syndrome, whereas populations raised in low predation environments lost this syndrome (Bell \& Sih 2007). It should also be noted, however, that differences between species could be a result of differences in how each species were reared in our study; as $G$. holbrooki were housed in isolation during the experimental period rather than in groups, and this could have had an influence on their behaviour (Gómez-Laplaza \& Morgan 2000, Bevan et al. 2018).

Interestingly, we found evidence that sociability is correlated to exploration in male $G$. affinis, but not females. Sociability has previously been found to be linked to dispersal in $G$. affinis, whereby asocial individuals tend to disperse further, faster and more frequently than social individuals when population densities are high (Cote et al. 2010b, 2011, 2013). Sociability-dependent dispersal in G. affinis has also been found to generate more severe impacts on native aquatic insect communities compared to random dispersal (Cote et al. 2017). Furthermore, dispersal propensity is higher in males compared to females (Cote et al. 2010b, 2011). Our results, together with these earlier studies, suggest that males (i.e. the more dispersive sex), that are asocial and bold, would be more likely to disperse away from established populations (i.e. high-density populations) and lead the invasion front. On the other hand, sociability appears to be independent of exploration and boldness in females. These sex-specific differences in personality and dispersal may thus have important implications for the spread and invasion of western mosquitofish, and for their impacts on native ecosystems, as the behavioural composition of range-front populations may be sexdependent. Conversely, due to a lack of behavioural differences between sexes, G. holbrooki invasions may be less prone to skewed sex ratios at the invasion front. A future study that explores the interaction between sex- and behavioural-dependent dispersal, and its 
410 implications for founder populations, would yield interesting insights into the spread

411 dynamics of invasive mosquitofish populations.

412

413 To conclude, our results suggest that different mosquitofish invasions have required different

414 behavioural tendencies to succeed, and that some of these behaviours are likely sex-

415 dependent. We found limited evidence of sex-specific personality in G. holbrooki, suggesting

416 that both sexes have an equal invasion potential. In contrast, differences in syndromes

417 between male and female $G$. affinis could be a mechanism that leads to sex-dependent

418 dispersal in this species, and thus unequal sex ratios at the leading edge, but future studies are

419 needed to test the validity of these hypotheses. Overall, identifying the behavioural

420 mechanisms that predict an individual's 'invasiveness' is difficult to tease apart between

421 species because each invasion is characterised by different abiotic and biotic interactions that

422 likely require different suites of behaviours (Felden et al. 2018, Mennan \& Laskowski 2018).

423 Future studies are needed to elucidate whether, in fact, personality variation between the

424 sexes can mediate the occurrence of sex-biased invasions.

425

426 ACKNOWLEDGEMENTS

427 ARC DP grant to DGC, AS, and BBMW (DP170100684). Monash University Animal Ethics 428 Approval BSCI/2013/20. JC was supported by a Fyssen Foundation fellowship and an AXA 429 research fund. JC and TB are also supported by a 2012-2013 BiodivERsA COFUND call for 430 research proposals, with the national funders ONEMA, DFG, SEPA. JC works at the 431 Laboratoire Evolution et Diversité Biologique (CNRS, UPS, UMR 5174), part of the 432 Laboratoire d'Excellence (LABEX) entitled TULIP (ANR-10-LABX-41). 
Aplin LM, Farine DR, Morand-Ferron J, Cockburn A, Thornton A \& Sheldon BC (2015). Experimentally induced innovations lead to persistent culture via conformity in wild birds. Nature 518:538.

Bates D, Maechler M, Bolker B \& Walker S (2015). Fitting linear mixed-effects models using lme4. Journal of Statistical Software 67:1-48.

Bell AM \& Sih A (2007). Exposure to predation generates personality in three-spined sticklebacks (Gasterosteus aculeatus). Ecology Letters 10:828-834.

Bell AM, Hankison SJ \& Laskowski KL (2009). The repeatability of behaviour: a metaanalysis. Animal Behaviour 77:771-783.

Bertram MG, Saaristo M, Martin JM, Ecker TE, Michelangeli M, Johnstone CP \& Wong BBM (2018). Field-realistic exposure to the androgenic endocrine disruptor $17 \beta$ trenbolone alters ecologically important behaviours in female fish across multiple contexts. Environmental Pollution 243:900-911.

Bevan PA, Gosetto I, Jenkins ER, Barnes I \& Ioannou CC (2018). Regulation between personality traits: individual social tendencies modulate whether boldness and leadership are correlated. Proceedings of the Royal Socieity B: Biological Sciences, $285: 20180829$

Biro PA \& Stamps JA (2008). Are animal personality traits linked to life-history productivity? Trends in Ecology and Evolution 23:361-368.

Biro PA, Adriaenssens B \& Sampson P (2014). Individual and sex-specific differences in intrinsic growth rate covary with consistent individual differences in behaviour. Journal of Animal Ecology 83:1186-1195.

Blackburn TM \& Duncan RP (2001). Establishment patterns of exotic birds are constrained by non-random patterns in introduction. Journal of Biogeography 28:927-939. 
Bolker BM, Brooks ME, Clark CJ, Geange SW, Poulsen JR, Stevens MHH \& White, JSS (2009). Generalized linear mixed models: a practical guide for ecology and evolution. Trends in Ecology \& Evolution 24:127-135.

Britton RH \& Moser ME (1982). Size specific predation by herons and its effect on the sexratio of natural populations of the mosquito fish Gambusia affinis. Oecologia 53:146151.

Chapple DG, Simmonds SM \& Wong BBM (2012). Can behavioral and personality traits 466 influence the success of unintentional species introductions? Trends in Ecology \& Evolution 27:57-64.

Chapple DG \& Wong BBM (2016). The role of behavioural variation across different stages of the introduction process. Chapter 2, Pages 7-25. In: Biological Invasions and Animal Behaviour (Eds: Weis JS, Sol D). Cambridge University Press, Cambridge.

Conover WJ, Johnson ME \& Johnson MM (1981). A comparative study of tests for homogeneity of variances, with applications to the outer continental shelf bidding data. Technometrics 23:351-361.

Cote J, Clobert J, Brodin T, Fogarty S \& Sih A (2010a). Personality-dependent dispersal: characterization, ontogeny and consequences for spatially structured populations. Philosophical Transactions of the Royal Society: Biological Sciences 365:40654076.

Cote J, Fogarty S, Weinersmith K, Brodin T \& Sih A (2010b). Personality traits and dispersal tendency in the invasive mosquitofish (Gambusia affinis). Proceeding of the Royal Society: Biological Sciences 277:1571-1579. in the invasive mosquitofish: group composition matters. Proceeding of the Royal Society: Biological Sciences 278:1670-1678 
484 Cote J, Fogarty S, Tymen B, Sih A \& Brodin T (2013). Personality-dependent dispersal cancelled under predation risk. Proceeding of the Royal Society: Biological Sciences 280:20132349

Cote J, Brodin T, Fogarty S \& Sih A (2017). Non-random dispersal mediates invader impacts on the invertebrate community. Journal of Animal Ecology 86:1298-1307.

Debecker S, Sanmartín-Villar I, de Guinea-Luengo M, Cordero-Rivera A \& Stoks R (2016). Integrating the pace-of-life syndrome across species, sexes and individuals:

covariation of life history and personality under pesticide exposure. Journal of Animal

Ecology $85: 726-738$.

Dingemanse NJ, Wright J, Kazem AJ, Thomas DK, Hickling R \& Dawnay N (2007). Behavioural syndromes differ predictably between 12 populations of three-spined stickleback. Journal of Animal Ecology 76:1128-1138.

Duckworth RA \& Badyaev AV (2007). Coupling dispersal and aggression facilitates the rapid range expansion of a passerine bird. Proceeding of National Academy of Science USA 104:15017-15022.

Fairbairn DJ, Blanckenhorn WU \& Székely T (2007). Sex, Size, and Gender Roles: Evolutionary Studies of Sexual Size Dimorphism. Oxford University Press, Oxford,

502 Felden A, Paris CI, Chapple DG, Haywood J, Suarez AV, Tsutsui ND, Lester PJ \& Gruber MAM (In Press). Behavioural variation and plasticity along an invasive ant introduction pathway. Journal of Animal Ecology, 87:1653-1666

505 Fogarty S, Cote J \& Sih A (2011). Social personality polymorphism and the spread of 506 invasive species: A model. The American Naturalist 177:273-287. 
Gomez-Laplaza LM \& Morgan EE (2000). Laboratory studies of the effects of short-term isolation on aggressive behaviour in fish. Marine and Freshwater Behaviour and Physiology, 33:63-102

Gruber J, Brown G, Whiting MJ \& Shine R (2017) Geographic divergence in dispersalrelated behaviour in cane toads from range-front versus range-core populations in Australia. Behavioral Ecology \& Sociobiology, 71:38

Gutowsky LFG \& Fox MG (2011). Occupation, body size and sex ratio of round goby (Neogobius melanostomus) in established and newly invaded areas of an Ontario river. Hydrobiologia, 671:27-35.

Foster WA \& Treherne JE (1981). Evidence for the dilution effect in the selfish herd from fish predation on a marine insect. Nature 293:466-467.

Fryxell DC, Arnett HA, Apgar TM, Kinnison MT \& Palkovacs EP (2015). Sex ratio variation shapes the ecological effects of a globally introduced freshwater fish. Proceeding of the Royal Society B 282: 2051970.

Harris S, Ramnarine IW, Smith HG \& Pettersson LB (2010). Picking personalities apart: estimating the influence of predation, sex and body size on boldness in the guppy Poecilia reticulata. Oikos 119:1711-1718.

Heinen-Kay JL, Schmidt DA, Stafford AT, Costa MT, Peterson MN, Kern EM \& Langerhan BR (2016). Predicting multifarious behavioural divergence in the wild. Animal behaviour 121:3-10.

Hoare D, Krause J, Peuhkuri N \& Godin JG (2000). Body size and shoaling in fish. Journal of $\quad$ Fish Biology 57:1351-1366.

Holway DA \& Suarez AV (1999). Animal behavior: an essential component of invasion biology. Trends in Ecology \& Evolution 14:328-330. 
531

Hulthén K, Chapman BB, Nilsson PA, Hansson LA, Skov C, Brodersen J, Vinterstare J \& Brönmark C (2017). A predation cost to bold fish in the wild. Scientific Reports $7: 1239$

Juette T, Cucherousset J \& Cote J (2014). Animal personality and the ecological impacts of freshwater non-native species. Current Zoology 60:417-427.

King AJ, Fürtbauer I, Mamuneas D, James C \& Manica A (2013). Sex-differences and temporal consistency in stickleback fish boldness. PLoS One 8:e81116.

Llewelyn J, Phillips BL, Alford RA, Schwarzkopf L \& Shine R (2010). Locomotor performance in an invasive species: cane toads from the invasion front have greater endurance, but not speed, compared to conspecifics from a long-colonised area. Oecologia 162:343-348

Marentette JR, Wang G, Tong S, Sopinka NM, Taves MD, Koops MA, Balshine S (2011). Laboratory and field evidence of sex-biased movement in the invasive round goby. Behavioral Ecology and Sociobiology, 65:2239-2249

Martín J, López P \& Cooper Jr. WE (2003) Lost of mating opportunities influences refuge use in the Iberian rock lizard, Lacerta monticola. Behavioral Ecology and Sociobiology 54:505-510.

McPeek MA (1992). Mechanisms of sexual selection operating on body size in the mosquitofish (Gambusia holbrooki). Behavioral Ecology, 3:1-12.

Mennen GJ \& Laskowski KL (2018). Defence is the best offence: invasive prey behaviour is more important than native predator behaviour. Animal Behaviour 138:157-64.

Michelangeli M, Wong BBM \& Chapple DG (2016a). It's a trap: sampling bias due to animal personality is not always inevitable. Behavioural Ecology 27:62-67. 
554 Michelangeli M, Chapple DG \& Wong BBM (2016b). Are behavioural syndromes sex

555

556

557

558

559

560

561

562

563

564

565

566

567

568

569

570

571

572

573

574

575

576

577 specific? Personality in a widespread lizard species. Behavioural Ecology \& Sociobiology 70:1911-1919.

Michelangeli M, Smith CR, Wong BBM \& Chapple DG (2017). Aggression mediates dispersal tendency in an invasive lizard. Animal Behaviour 133:29-34.

Michelangeli M, Goulet CG, Kang HS, Wong BBM \& Chapple DG (2018a). Integrating thermal physiology within a syndrome: locomotion, personality and habitat selection in an ectotherm. Functional Ecology 32:970-981.

Michelangeli M, Chapple DG, Goulet CG, Bertram MG \& Wong BBM (In Press). Behavioural syndrome vary among geographically distinct population, Behavioral Ecology.

Mishra A, Tung S, Shreenidhi PM, Aamir Sadiq MA, Shree Struti VR, Chakraborty PP \& Dey S (2018) Sex differences in dispersal syndrome are modulated by environment and evolution. Philosophical Transactions of the Royal Society: Biological Sciences. 373: 20170428 .

Miller TE \& Inouye BD (2013) Sex and stochasticity affect range expansion of experimental invasions. Ecology Letters 16:354-361.

Moran NP, Mossop KD, Thompson RM \& Wong BBM (2016). Boldness in extreme environments: temperament divergence in a desert-dwelling fish. Animal Behaviour 122:125-133.

Phillips BL \& Suarez AV (2012). The role of behavioural variation in the invasion of new areas. In: Behavioural responses to a Changing World: Mechansims and consequences (Ed. Wong BBM \& Candolin U), Oxford University Press, Oxford, UK, 190-200. 
578 Pilastro A, Benetton S, Bisazza A (2003). Female aggregation and male competition reduce costs of sexual harassment in the mosquitofish Gambusia holbrooki. Animal Behaviour 65:1161-1167

Pintor LM, Sih A \& Kerby JL (2009). Behavioral correlations provide a mechanism for explaining high invader densities and increased impacts on native prey. Ecology

Polverino G, Santostefano F, Díaz-Gil C \& Mehner T (2018). Ecological conditions drive pace-of-life syndromes by shaping relationships between life history, physiology and behaviour in two populations of Eastern mosquitofish. Scientific Reports. 8:14673.

Pyke GH (2005). A review of the biology of Gambusia affinis and G. holbrooki. Reviews in Fish Biology and Fisheries. 15:339-365.

Pyke GH (2008). Plague minnow or mosquito fish? A review of the biology and impacts of introduced Gambusia species. Annual Review of Ecology, Evolution, and Systematics 39:171-191.

R Core Team (2016). R: A language and environment for statistical computing. R Foundation for Statistical Computing, Vienna, Austria. https://www.R-project.org/

Rebrina F, Skejo J, Lucić A, Hudina S (2015). Triat variability of the signal crayfish (Pacifastacus leniusculus) in a recently invaded region relects potential benefits and trade-offs during dispersal. Aquatic Invasions 10:41-50.

Rehage JS \& Sih A (2004). Dispersal behavior, boldness, and the link to invasiveness: a comparison of four Gambusia species. Biological Invasions 6:379-391.

600

Rehage JS, Barnett BK \& Sih A (2005). Behavioral responses to a novel predator and competitor of invasive mosquitofish and their non-invasive relatives (Gambusia sp.). Behavioral Ecology and Sociobiology 57:256-266. 
602 Rehage JS, Cote J \& Sih A (2016). The role of dispersal behaviour and personality in post-

603

604

605

606

607

608

609

610

611

612

613

614

615

616

617

618

619

620

621

622

623

624

625

626 establishment spread. Chapter 7, Pages 96-115. In: Biological Invasions and Animal Behaviour (Eds: Weis JS, Sol D). Cambridge University Press, Cambridge.

Renault D, Laparie M, McCauley SJ \& Bonte D (2018). Environmental Adaptations, Ecological Filtering, and Dispersal Central to Insect Invasions. Annual Review of Entomology 63:345-368.

Royston P (1995). A remark on algorithm AS 181: the $W$-test for normality. Journal of the Royal Statistical Society Series C: Applied Statistics 44:547-551.

Shaw AK, Kokko H \& Neubert MG (2018) Sex difference and Allee effects shape the dynamics of sex-structured invasions. Journal of Animal Ecology 87:36-46.

Shine R (1989). Ecological causes for the evolution of sexual dimorphism: a review of the evidence. The Quarterly Review of Biology 64:419-461.

Shulse CD, Semlitsch RD \& Trauth KM (2013). Mosquitofish dominate amphibian and invertebrate community development in experimental wetlands. Journal of Applied Ecology 50:1244-1256.

Sih A, Bell AM \& Johnson JC (2004). Behavioral syndromes: an ecological and evolutionary overview. Trends in Ecology \& Evolution 19:372-378.

Sih A, Cote J, Evans M, Fogarty S \& Pruitt J (2012). Ecological implications of behavioural syndromes. Ecology Letters 15:278-289.

Tingley R, Romagosa CM, Kraus F, Bickford D, Phillips BL \& Shine R (2010). The frog filter: amphibian introduction bias driven by taxonomy, body size and biogeography. Global Ecology and Biogeography 19:496-503.

Tomkins P, Saaristo M, Bertram MG, Michelangeli M, Tomkins RB \& Wong BBM (2018). An endocrine-disrupting agricultural contaminant impact sequential female mate choice in fish. Environmental Pollution 237:103-110. 
627 Trochet A, Courtois EA, Stevens VM, Baguette M, Chaine A, Schmeller DS, Clobert J \& 628 Wiens JJ (2016). Evolution of sex-biased dispersal. The Quarterly Review Biology $629 \quad 91: 297: 320$.

630 Ward AJ, Thomas P, Hart PJ \& Krause J (2004). Correlates of boldness in three-spined $631 \quad$ sticklebacks (Gasterosteus aculeatus). Behavioral Ecology and Sociobiology 55:561632568.

633 Wilson AD, Godin JGJ \& Ward AJ (2010). Boldness and reproductive fitness correlates in 634 the eastern mosquitofish, Gambusia holbrooki. Ethology 116:96-104.

635 Wolf M \& Weissing FJ (2012). Animal personalities: Consequences for ecology and 636 evolution. Trends in Ecology \& Evolution 27:452-461. 
637 FIGURE LEGENDS

638 Figure 1. Mean ( \pm standard error) trait-level differences of females (black) and males (blue) 639 across two Gambusia species (G. affinis and G. holbrooki) in A) tendency to shoal (i.e. time 640 spent within $2 \mathrm{~cm}$ social zone; sociability), B) boldness score (i.e. log maximum time allowed 641 for fish to exit the refuge (2700 s) minus the log latency (s) to exit from the refuge; boldness) 642 and C) tendency to explore a novel environment (\% of novel environment explored; 643 exploration). Sample sizes differed between species; G. affinis (female: $\mathrm{n}=112$, male: $\mathrm{n}=$ 644 111), G. holbrooki (female: $\mathrm{n}=25$, male: $\mathrm{n}=25$ ).

645

646 Figure 2. Sex regression lines for relationship between tendency to explore a novel 647 environment (\% of novel environment explored) and boldness score (i.e. log maximum time 648 allowed for fish to exit a refuge (2700 s) minus the log latency (s) to exit from the refuge) 649 within two mosquitofish species, Gambusia affinis (top; female: $\mathrm{n}=112$, male: $\mathrm{n}=111$ ) and 650 Gambusia holbrooki (bottom; female: $\mathrm{n}=25$, male: $\mathrm{n}=25$ ). Males $=$ dashed lines, triangles, 651 females $=$ solid line, circles. 
652 Table 1: Main effects of sex, body length and trial on a) time spent shoaling with conspecifics, b) time to re-emerge from a refuge, and c)

653 percentage of novel environment explored, in Gambusia holbrooki (female: $n=25$; male: $n=25$ ). Models were first compared with and without

654 the interaction terms using Likelihood ratio tests $\left(G^{2}\right)$. Interaction terms were removed from the final models if were non-significant. Results

655 were obtained from linear mixed effects models (LMM) and contained individual ID as a random factor.

\begin{tabular}{llllll}
\hline Behaviour & Fixed effects & $G^{2}$ & $\beta$ & $t$ & $p$ \\
\hline a) Time spent shoaling & Sex & - & 0.498 & 1.474 & 0.147 \\
& Body length & - & 0.004 & -0.085 & 0.932 \\
& Trial & - & 0.170 & 1.393 & 0.170 \\
& Sex $\times$ trial & 1.392 & - & - & 0.238 \\
& Sex $\times$ body length & 0.150 & - & - & 0.698 \\
b) Time to re-emerge from refuge & Sex & - & 0.270 & 0.795 & 0.431 \\
& Body length & - & 0.059 & 1.085 & 0.284 \\
& Trial & - & 0.277 & 1.440 & 0.156 \\
& Sex $\times$ trial & 3.368 & - & - & 0.066 \\
& Sex $\times$ body length & 0.071 & - & - & 0.790 \\
c) \% of novel environment explored & Sex & - & 0.022 & 0.382 & 0.704 \\
& Body length & - & 0.014 & 1.543 & 0.129 \\
& Trial & - & $\mathbf{0 . 0 9 3}$ & $\mathbf{2 . 7 7 2}$ & $\mathbf{0 . 0 0 8}$ \\
& Sex $\times$ trial & 0.031 & - & - & 0.860 \\
& Sex $\times$ body length & 0.281 & - & - & 0.596 \\
\hline
\end{tabular}

$656 G^{2}=$ chi-squared value. $\beta=$ co-efficient. Bold refers to significant terms a $P<0.05$. Note that each species differed substantially in sample size. 
658 Table 2: Main effects of sex and body length on a) time spent shoaling with conspecifics, b) time to re-emerge from a refuge, and c) percentage

659 of novel environment explored, in Gambusia affinis (female: $n=110$; male: $n=112$ ). Results were obtained from linear models. Bold terms 660 indicate significant results

\begin{tabular}{|c|c|c|c|c|c|}
\hline Behaviour & Fixed effects & $F$ & $\bar{\beta}$ & $t$ & $p 661$ \\
\hline \multirow[t]{3}{*}{ a) Time spent shoaling } & Sex & - & 0.612 & 2.632 & 0.009 \\
\hline & Body length & - & -0.052 & -1.917 & 0.0592 \\
\hline & Sex $\times$ body length & 0.214 & - & - & 0.644 \\
\hline \multirow[t]{3}{*}{ b) Time to re-emerge from refuge } & Sex & - & 3.356 & 2.483 & 0.014 \\
\hline & Body length & - & 0.008 & 0.326 & 0.745 \\
\hline & Sex $\times$ body length & 5.394 & 0.128 & 2.323 & $0.069^{4}$ \\
\hline \multirow[t]{3}{*}{ c) $\%$ of novel environment explored } & Sex & - & 0.022 & 0.800 & 0.425 \\
\hline & Body length & - & $<0.001$ & 0.164 & $0.8 \%(0)$ \\
\hline & Sex $\times$ body length & 1.931 & - & - & 0.166 \\
\hline
\end{tabular}

667

668

669

670

671

672 
673 Table 3: Correlation coefficients $(r)$ for each behavioural correlation estimated using Spearman rank correlation tests and Fisher $z$ statistic

674 comparing the sex-specific effect sizes. Bold scores refer to significant correlation coefficients.

\begin{tabular}{|c|c|c|c|c|c|c|c|c|}
\hline \multirow[b]{2}{*}{ Species } & \multirow[b]{2}{*}{ Correlation } & \multicolumn{2}{|c|}{$\sigma^{1}$} & \multicolumn{2}{|c|}{ q } & \multirow[b]{2}{*}{ Fisher $z$} & \multicolumn{2}{|c|}{ Total $\left(\jmath^{\lambda}+q\right)$} \\
\hline & & $r$ & $p$ & $r$ & $p$ & & $r$ & $p$ \\
\hline \multirow[t]{3}{*}{ G. holbrooki } & Boldness - Exploration & -0.11 & 0.46 & 0.26 & 0.07 & $z=-1.82, p=0.07$ & 0.08 & 0.40 \\
\hline & Sociability - Exploration & -0.03 & 0.84 & 0.11 & 0.43 & $z=-0.70, p=0.48$ & 0.05 & 0.59 \\
\hline & Sociability - Boldness & 0.01 & 0.99 & 0.03 & 0.86 & $z=-0.12, p=0.90$ & 0.01 & 0.93 \\
\hline \multirow[t]{3}{*}{ G. affinis } & Boldness - Exploration & 0.28 & $<0.01$ & 0.32 & $<0.01$ & $z=-0.33, p=0.74$ & 0.26 & $<0.01$ \\
\hline & Sociability - Exploration & 0.21 & 0.02 & 0.05 & 0.61 & $z=1.19, p=0.23$ & 0.14 & 0.04 \\
\hline & Sociability - Boldness & 0.10 & 0.30 & 0.10 & 0.30 & $z=0.01, p=0.99$ & 0.08 & 0.24 \\
\hline
\end{tabular}

675

676 

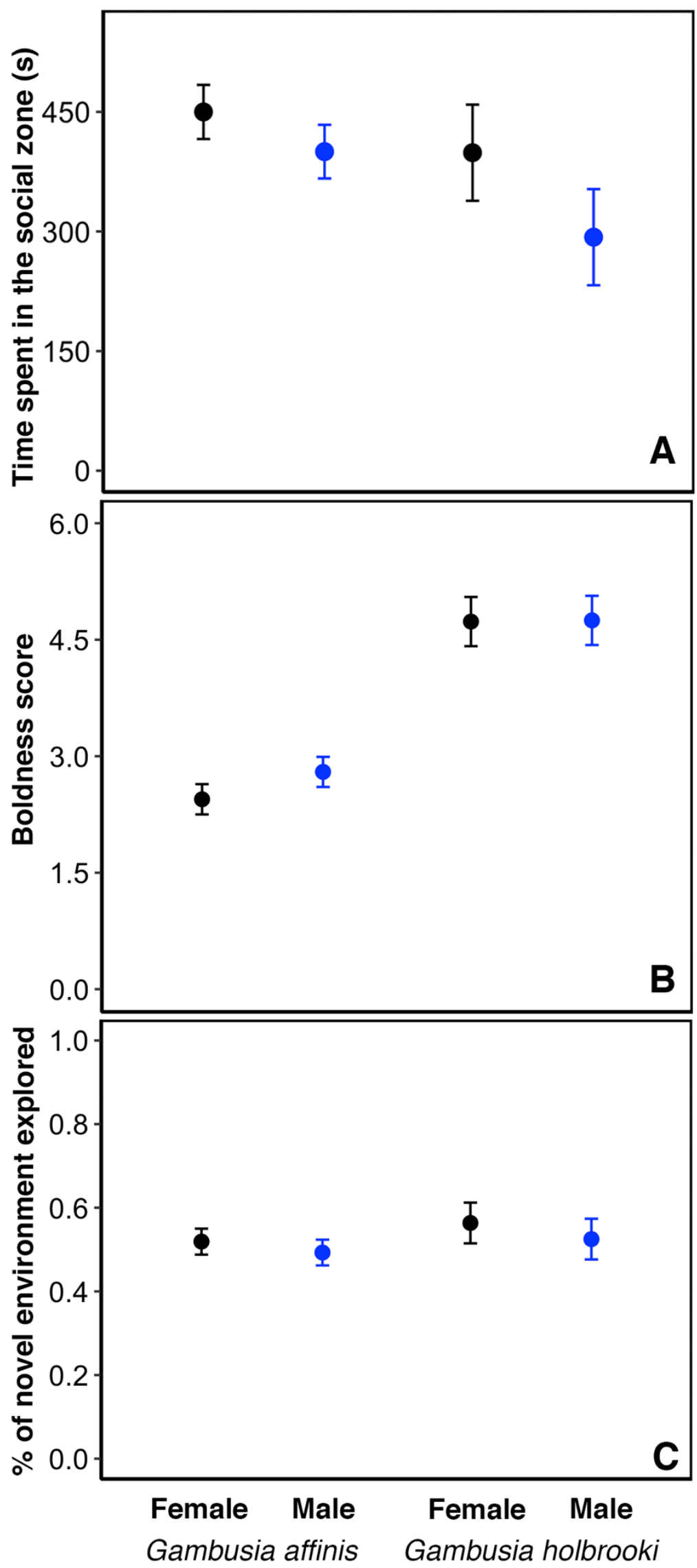

Figure 1. 


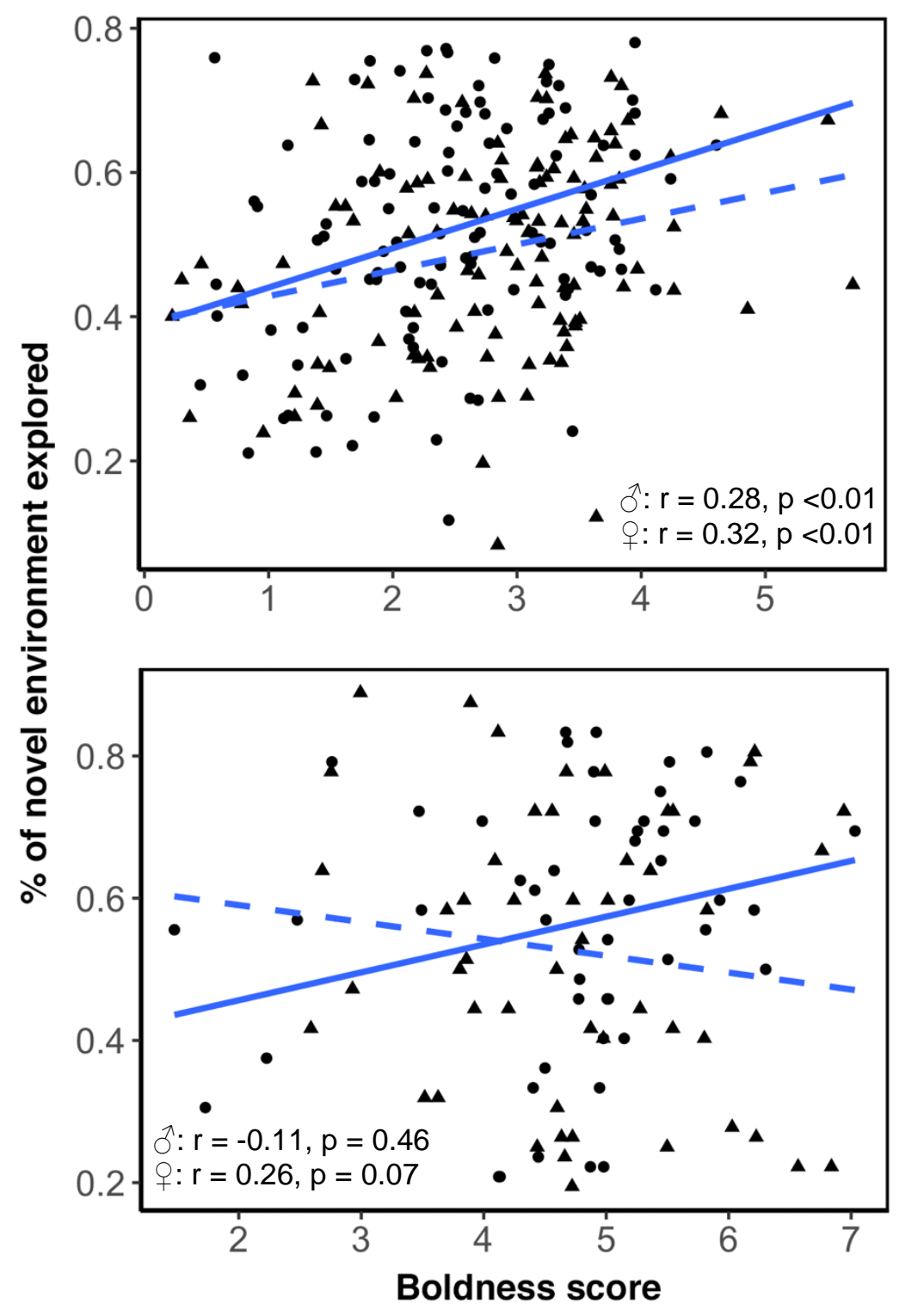

Figure 2. 